\title{
Risk Management Analysis in Software Projects which Use the Scrum Framework
}

\author{
Breno Gontijo Tavares ${ }^{1}$ Carlos Eduardo Sanches da Silva ${ }^{1} \quad$ Adler Diniz de Souza $^{2}$ \\ ${ }^{1}$ Instituto de Engenharia de Produção e Gestão \\ Universidade Federal de Itajubá, UNIFEI \\ Itajubá, Brazil \\ 2Instituto de Matemática e Computação \\ Universidade Federal de Itajubá, UNIFEI \\ Itajubá, Brazil
}

\begin{abstract}
Studies show one of the reasons for the failure of the software projects is the absence of Risk Management or its improper application. The adoption of Scrum Framework on software projects is increasing. However, the Scrum does not have specific Risk Management activities. In this scenario, this paper presents the results of a survey applied using qualitative approach, in order to analyze how Risk Management is carried out in software projects, which use Scrum. The research method adopted was the case study and the research instrument for data collection was developed based on scientific articles and the application of structured interviews. As a result, this paper presents Risk Management practices which achieved greater and lower agreement among respondents and literature. It was found that Risk Management must be applied continuously in a feedback loop. Furthermore, Scrum projects must not have a high formal planning level, even for the high risk ones. This result does not converge to the literature. The research verified that the Risk Management in Scrum projects is performed differently from its application on traditional methodologies. The framework has native resources, but the use of the classic Risk Management processes must be incorporated and adapted to Scrum.
\end{abstract}

Keywords: Risk Management; Scrum; Software; Case Study.

\section{INTRODUCTION}

Software projects are complex enterprises in any context and they are particularly susceptible to failure [1]. Most of these projects run over budget are terminated prematurely or fall far short of meeting user expectations and business functionalities [2].

In this scenario, software development industry has been using agile methodologies to manage projects instead of using traditional methodologies $[3,4]$. This is because traditional methodologies are commonly considered heavy, unlike agile methodologies, which aim to provide light approaches to projects [5].

The Scrum framework is the most used agile methodology in Software Project Management [6, 7, 8], which provides a set of good practices aimed at fast delivery of value to the customer.

However, Risk Management, which can reduce uncertainty and increase the chances of success in software projects $[9,10$, $11,12]$, is conducted in an implicitly way in projects which use agile methodologies $[13,14,15]$. Futhermore, risk management in agile projects needs to be improved without threatening the agility of projects [16].

Nyfjord and Kajko-Mattsson [15] have done a comparative analysis between the traditional and agile risk management approaches. The authors assert that agile methodologies do not provide any risk management taxonomy and they suggest that agile methodologies should learn to integrate traditional risk management practices in order to ensure an effective risk management.

Furthermore, the literature about Risk Management applied in software development projects which use agile methodologies is scarce $[17,18]$. There are few articles describing the Risk Management application with agile methodologies. However, these articles do not emphasize the process of how a team establishes, prioritizes and takes action about risks [19].

Therefore, the aim of this work is to answer the following research question: How Risk Management is performed in projects that use Scrum framework?

From this survey question, this paper aims to analyze the Risk Management in Scrum projects and establishes the following specific objectives:

- Identify applied Risk Management practices in software development;

- Conduct a case study in software projects that use the Scrum, in order to analyze the respondents agreement with Risk Management practices identified in scientific literature.

This paper is organized as follows: Section 1 presents the objectives and research contributions; Section 2 performs the literature review about Risk Management in Scrum; Section 3 presents the research classification, the case study design and research protocol; Section 4 presents the data collection and its results, and finally, Section 5 presents the discussions, conclusions and suggestion for further researches.

\section{RISK MANAGEMENT IN THE SCRUM FRAMEWORK}

Scrum life cycle provides the monitoring of the product that is being developed and identifies impediments. Some authors define impediment as a project risk [20,21], while other authors state that there are differences between these two concepts [22, $23,24]$.

This paper uses the impediment definition proposed by Jakobsen and Johnson [22], as a problem that has already occurred and it is affecting project progress and distinguishing risk and impediment definitions.

In this context, when Risk Management is used in Scrum projects, it enables the prevention of impediments, 
implementing proactive actions to inhibit project risks to become further impediments [22].

According to [25], Scrum framework uses an iterative and incremental approach to optimize predictability and risk control. The authors state that the use of Sprints also supports Risk Management, since it limits risk to one calendar month of cost [25].

However, other authors believe that the Scrum and agile methodologies in general do not suggest specific activities to perform Risk Management [13, 14, 15], and this management in Scrum is not as good as traditional methodologies [26]. According to [26], the Scrum serves only for risks identification practice, however, it does not offer ways to analyze and manage them.

Despite the importance of Risk Management to project success, few scientific studies were identified in a survey conducted in the three following databases: Web of Science, Scielo and Google Scholar. The words "Scrum", "Project", "Risk" and "Management" were searched in articles titles without returning any results.

\section{METHODOLOGY}

The research method used was a case study (Yin, 2009), for the purpose of exploration. The methods used for data collection were the questionnaire and semi-structured interviews.

There were selected software projects that used the Scrum Framework. One of the selection criteria was the relevance of these projects in terms of invested effort, which was established a minimum of 1500 hours for each project.

As selection result, there were identified 10 software projects that met selection criteria, 2 of them under development and 8 finished projects. Five projects were developed for medium-sized companies while the other five were developed for large-sized companies. This classification was based on the European Comission [27] proposal, which establishes annual revenue greater than 50 million euros for large-sized companies, and annual revenue between 10 and 50 million euros for medium-sized companies.

Aiming to know these projects characteristics, their classification was performed according to diamond model, proposed by [28]. The model, also known as NTCP, provides four dimensions for project classification: Novelty, Technology Complexity and Pace. This Model is considered to be a suitable framework for project classification [29]. Other scientific researches used NTCP model for project classification [30, 31, 32].

Scrum Masters of these projects responded to a structured questionnaire applied through an on-site interview, aiming to classify each project according to NTCP model. The classification was validated by the senior managers of these projects through interviews.

Most projects were classified as "Platform", "MediumTech", "System" and "Fast/Competitive". These classifications allow the identification of one of this research limitations, because applying the same research protocol in a different environment may present other results.

These Scrum Masters attended to another on-site interview to identify the adherence of the ten projects to the roles, events, artifacts and rules of Scrum. Assessing adherence of these projects to Scrum was performed because the possibility of them do not implement Scrum in its entirety.

This analysis was performed following the 4 steps:

1. Identifying Scrum practices: this step aimed the lifting of the main features of Scrum according to the Scrum Guide book [25];

2. Preparing the questionnaire: the questionnaire was designed with seventeen closed questions, using a Likert scale of six points and classified according to the chapters of the Scrum Guide.

3. Performing the interviews: the Scrum Masters who worked on the ten projects were individually interviewed where the structured questionnaire was applied.

4. Analysing the results: the analysis revealed the smaller and larger adhesions, beyond the average adherence of each project to Scrum.

The Table 1 presents the questionnaire applied to identify the adherence of the then projects to the Scrum framework.

TABLE 1. QUESTIONNAIRE TO IDENTIFY THE ADHERENCE LEVEL TO SCRUM THE COMPLETE TABLE CAN BE SEEN AT THE ADDRESS https://goo.gl/Mh1Cem

\begin{tabular}{|c|c|c|c|c|}
\hline \multicolumn{2}{|r|}{ Scrum Practices } & \multicolumn{2}{|r|}{ Questions } & \multirow{2}{*}{ Classification } \\
\hline $\mathbf{N}^{0}$ & Description & $\mathbf{N}^{0}$ & Description & \\
\hline 1 & $\begin{array}{l}\text { Scrum users must } \\
\text { frequently inspect Scrum } \\
\text { artifacts and progress } \\
\text { toward a Sprint Goal to } \\
\text { detect undesirable variances } \\
\text { [25]. }\end{array}$ & 1 & $\begin{array}{l}\text { The team, frequently, } \\
\text { inspect Scrum artifacts } \\
\text { and progress toward } \\
\text { Sprint Goal to detect } \\
\text { undesirable variances. }\end{array}$ & Scrum Theory \\
\hline 11 & $\begin{array}{l}\text { When a Product Backlog } \\
\text { item or an Increment is } \\
\text { described as "Done", } \\
\text { everyone must understand } \\
\text { what "Done" means [25]. }\end{array}$ & 17 & $\begin{array}{l}\text { When a Product Backlog } \\
\text { item or an Increment is } \\
\text { described as "Done", } \\
\text { everyone must } \\
\text { understand what "Done" } \\
\text { means. }\end{array}$ & $\begin{array}{c}\text { Artifact } \\
\text { Transparency }\end{array}$ \\
\hline
\end{tabular}

The results of the adherence study of the ten projects presents that three projects had no adherence to Scrum in at least one of the questions in the questionnaire. The project that received the highest average adherence to Scrum was $89.41 \%$ while the project who got the lowest value was $43.53 \%$.

The differences in results between the projects must be justified considering the different context of each project, where for each one has defined a management scope to meet the project specific needs. This setting allowed the choice of what artifacts, events, and rules of Scrum that would be used in the project life cycle.

To develop the research protocol, a survey was conducted in the three databases presented in the Table 2.

TABLE 2 - DATABASES USED TO DEVELOP THE RESEARCH PROTOCOL

\begin{tabular}{|c|l|}
\hline Database & \multicolumn{1}{c|}{ Description } \\
\hline $\begin{array}{l}\text { Web of } \\
\text { Science }\end{array}$ & $\begin{array}{l}\text { The Web of Science is the largest repository of scientific } \\
\text { papers worldwide [33, 34]. }\end{array}$ \\
\hline Scielo & $\begin{array}{l}\text { The Scielo database represents one of the major scholarly } \\
\text { communication programs in the developing countries and is a } \\
\text { pioneer in the adoption of Open Access [35]. }\end{array}$ \\
\hline $\begin{array}{l}\text { Google } \\
\text { Scholar }\end{array}$ & $\begin{array}{l}\text { Google Scholar is a free web-based database which indexes } \\
\text { literature in a wide variety of formats [36] and has steadily } \\
\text { grown importance in the academic library community } \\
{[37] .}\end{array}$ \\
\hline
\end{tabular}


The following terms were searched in the articles titles:

(1) Software AND Project AND Risk AND Management

(2) Agile AND Project AND Risk AND Management

(3) Scrum AND Project AND Risk AND Management

All these search terms were combined by using the Boolean "OR" operator, which entails that an article only had to include any one of the terms to be retrieved. That is, we searched: $1 \mathrm{OR}$ 2 OR 3 and we identified 138 articles.

This research considered Impact Factor (IF) from the Journal Cication Reports (JCR) as another article selection criteria, aiming to increase the Risk Management practices reliability. From the 138 identified articles initially, only 11 possess IF from JCR.

The 11 articles were deeply analyzed aiming to gather the Risk Management practices. There were 3 of the 11 analyzed articles that did not contain any of those practices and so could not be used in the research protocol development.

It is important to mention that the considered articles are not specifically about Scrum projects. However, they reference Risk Management applied to software projects. There was not identified any article that specifically analyzes Risk Management in this framework and that attended the selection criteria established for the research protocol.

The 8 articles were deeply analyzed and 35 Risk Management practices were identified considering only software projects. The identified practices were used to generate 40 questions. The questions were developed using a 6-point Likert scale since it does not allow the respondents to choose a central point, which can be considered as neutral or without opinion [38].

The questionnaire was submitted to two pilot tests in two different companies that develop software projects and use the Scrum framework for more than 4 years. Considering the total sum of the modifications from the two tests, there were 31 modifications on 40 questions or $77,5 \%$ of the questionnaire.

The Table 3 presents the practices and their respective Risk Management questions, after the application of the pilot tests.

TABLE 3 - RISK MANAGEMENT PRACTICES AND QUESTIONS THE COMPLETE TABLE CAN BE SEEN AT THE ADDRESS https://goo.gl/4JFTIM

\begin{tabular}{|c|c|c|c|}
\hline \multicolumn{2}{|c|}{ Risk Management Practices } & \multicolumn{2}{c|}{ Questions } \\
\hline $\mathbf{N}^{\circ}$ & \multicolumn{1}{|c|}{ Description } & $\mathbf{N}^{\circ}$ & \multicolumn{1}{c|}{ Description } \\
\hline 1 & $\begin{array}{l}\text { Senior management holds the } \\
\text { key to establishing an } \\
\text { organization that encourages } \\
\text { functional' Risk } \\
\text { Management behavior [39]. }\end{array}$ & 1 & $\begin{array}{l}\text { Senior management holds } \\
\text { the key to establishing an } \\
\text { organization that encourages } \\
\text { Risk Management behavior. }\end{array}$ \\
\hline 35 & $\begin{array}{l}\text { Cannot be stated that formal } \\
\text { Risk Management } \\
\text { procedures produce better } \\
\text { results than internal methods } \\
\text { (ad hoc internally developed } \\
\text { procedures) [12]. }\end{array}$ & 40 & $\begin{array}{l}\text { Cannot be stated that formas } \\
\text { Risk Management } \\
\text { procedures produce better } \\
\text { results than internal methods } \\
\text { (ad hoc internally developed } \\
\text { procedures). }\end{array}$ \\
\hline
\end{tabular}

Beyond the research protocol 40 questions, there were developed 7 questions of external validation and 4 questions to supplement the questionnaire.

\section{RESULTS ANALYSIS}

The field research was performed throught on-site interviews, providing a better communication between the interviewer and respondents. Interviews from 40 to 60 minutes were applied for the 21 members of the selected projects. This population represented $100 \%$ of the employees that work on the project and that still worked on the organization.

The results of the external validation are presented by the Table 4.

TABLE 4 - EXTERNAL VALIDATION RESULTS

\begin{tabular}{|c|c|}
\hline Questions & Results \\
\hline Education level & $\begin{array}{l}\text { - } \mathbf{6 6 , 6 7 \%}=\text { Specialization } \\
\text { - } 33,33 \%=\text { Graduation } \\
\text { - } 0 \% \quad \text { = Technician, High School, } \\
\text { Incomplete Graduation, Master and } \\
\text { Doctor Degree }\end{array}$ \\
\hline $\begin{array}{l}\text { Which functions have you } \\
\text { performed? }\end{array}$ & $\begin{array}{ll}\text { - } & \mathbf{9 0 , 4 8 \%}=\text { Developer } \\
\text { - } & 47,62 \%=\text { Scrum Master } \\
\text { - } & 19,05 \%=\text { Owner } \\
\end{array}$ \\
\hline $\begin{array}{l}\text { How long is your experience } \\
\text { in software projects } \\
\text { development? }\end{array}$ & $\begin{array}{l}\text { - } \mathbf{8 0 , 9 5 \%}=\text { Beyond } 4 \text { years } \\
\text { - } 9,52 \%=\text { From } 1 \text { to } 2 \text { years } \\
\text { - } 9,52 \%=\text { From } 2 \text { to } 4 \text { years } \\
\text { - } 0 \%=\text { Less than } 1 \text { year }\end{array}$ \\
\hline $\begin{array}{l}\text { How long is your experience } \\
\text { in Scrum? }\end{array}$ & $\begin{array}{l}\text { - } \mathbf{4 2 , 8 6 \%}=\text { From } 2 \text { to } 4 \text { years } \\
\text { - } 33,33 \%=\text { From } 1 \text { to } 2 \text { years } \\
\text { - } 14,29 \%=\text { Less than } 1 \text { years } \\
\text { - } 9,52 \%=\text { Beyond } 4 \text { years }\end{array}$ \\
\hline
\end{tabular}

The interview identified that some of the interviewed professionals possess certifications in the areas of Project Management, Scrum and Risk Management, as follows on Table 5.

TABLE 5 - PROFESSIONAL CERTIFICATIONS

\begin{tabular}{|l|c|}
\hline \multicolumn{1}{|c|}{ Certification } & Interviewees \\
\hline PMP (Project Management Professional) & 4 \\
\hline PSM (Professional Scrum Master) & 2 \\
\hline PMI-RMP (Risk Management Professional) & 1 \\
\hline
\end{tabular}

It is important to mention that the interviewer possess the three certifications presented on the Table 5.

The external validation was ensured through the profile of the interviewed professionals that work or worked in one of the ten selected projects.

Aiming to obtain the internal consistency of the questionnaire, the Cronbach Alpha [40], Theta coefficient $(\Theta)$ [41] and the Omega Indicator $(\Omega)[42]$ were calculated. The values obtained were, respectively, $0.8302,0.8320$ and 0.8875 , which are within acceptable values [40, 41, 42].

In order to obtain a deeper analysis for the questions results, Table 6 was generated through the software Minitab 17®, performing the descriptive statistics for the Risk Management practices. 
TABLE 6 - THE QUESTIONNAIRE AND DESCRIPTIVE STATISTICS

THE COMPLETE TABLE CAN BE SEEN AT THE ADDRESS https://goo.gl/6t1ZII

\begin{tabular}{|c|c|c|c|c|c|c|c|c|c|}
\hline $\mathbf{N}^{\circ}$ & Practices & & Questions & Mean & S.E. Mean & $\begin{array}{l}\text { Standard } \\
\text { deviation }\end{array}$ & Minimum & Median & Maximum \\
\hline 32 & $\begin{array}{l}\text { Risk management should be performed } \\
\text { continuously in a feedback loop so that } \\
\text { problematic situations can be } \\
\text { dynamically detected and adjusted [43]. }\end{array}$ & 37 & $\begin{array}{l}\text { Risk Management should be } \\
\text { performed continuously in a feedback } \\
\text { loop so that problematic situations can } \\
\text { be dynamically detected and adjusted. }\end{array}$ & 4,762 & 0,118 & 0,539 & 3 & 5 & 5 \\
\hline 19 & $\begin{array}{l}\text { Since every project element may be } \\
\text { related to uncertainty events that cause } \\
\text { prejudice to a software project, } \\
\text { development teams must reuse } \\
\text { knowledge about risks that should occur } \\
\text { in applications developed with these } \\
\text { elements [44]. }\end{array}$ & 21 & $\begin{array}{l}\text { The development teams must reuse } \\
\text { knowledge about risks (lessons } \\
\text { learned). }\end{array}$ & 4,619 & 0,109 & 0,498 & 4 & 5 & 5 \\
\hline 16 & $\begin{array}{l}\text { Software development projects require } \\
\text { high levels of Formal Planning for high } \\
\text { Risk Exposure projects and low levels of } \\
\text { Formal Planning for low Risk Exposure } \\
\text { projects [45]. }\end{array}$ & 18 & $\begin{array}{l}\text { Software development projects require } \\
\text { high levels of Formal Planning for } \\
\text { high Risk Exposure projects and low } \\
\text { levels of Formal Planning for low } \\
\text { Risk Exposure projects. }\end{array}$ & 1,667 & 0,261 & 1,197 & 0 & 2 & 3 \\
\hline 30 & $\begin{array}{l}\text { After the initial round of risk } \\
\text { identification, risk management tended } \\
\text { to be relegated to the project manager, } \\
\text { who often did little more than informally } \\
\text { update the risk register before each } \\
\text { steering committee meeting [1]. }\end{array}$ & 32 & $\begin{array}{l}\text { After the initial round of risk } \\
\text { identification, Risk Management } \\
\text { tended to be relegated to the SCRUM } \\
\text { MASTER. }\end{array}$ & 1,619 & 0,253 & 1,161 & 0 & 1 & 3 \\
\hline
\end{tabular}

As can be observed in the Table 6 , the practice with highest average is related to continuously accomplishing the Risk Management in a feedback loop, where Risk Management must be updated in each iteration with new project data, and then generate new estimates [41]. This means that the respondents had higher agreement with this practice when it is about a Scrum project rather than other identified Risk Management practices. This result converges to the Scrum life cycle that possess ceremonies of which the focus is to obtain a constant feedback $[46,47]$. The authors [48] complements that the continuous feedback is the key factor for projects success.

The practice with the second highest average refers to the reuse of risks knowledge or the lessons learned. This result shows the respondents believe that this knowledge should be used in Scrum projects. The lessons learned are commonly used within Scrum life cycle and are mainly identified and discussed in retrospective meetings [49].

On the other hand, the research identified that the Risk Management practice with the lowest average is related to the Risk Management tend to be relegated to the Scrum Master after the initial round of risk identification. It shows that the respondents in general agree less with this practice, in other words, that they believe Risk Management occurs within other project occasions. The risks identification on Scrum is iterative, occurring during daily meetings [20] or any other Scrum meeting [50].

The practice with the second lowest average refers to the fact that high-risk projects demand high formal planning levels and low-risk projects demand low formal planning levels. The respondents in general did not agree with this practice, justifying the Scrum processes must be agile, even in high risk projects, and a high level formal planning impacts negatively on agility. This opinion is different than that found in the literature. For example, [51] defends that agile methodologies must be used considering the project context for adapting the processes.

There were also identified results that do not converge to the Scrum literature. For example, the practice related to the Scrum Master unavailability to implement a formal Risk Management process. The respondents in general believe that, in practice, the Scrum Master is not concerned with the implementation of formal processes and his role is focused on assisting the development team.

On the other hand, some authors claim that the Scrum Master is responsible for managing Scrum processes [52] and other processes used for developing the software [53]. The authors [54] claim that the Scrum Master is responsible for the implementation of the project risks plan.

During the same interview were applied four additional questions, whose aim was to complement the Risk Management questionnaire in Scrum.

All respondents believe that Scrum has no specific activities for the practice of risk management, but that the ceremonies of the framework allow the treatment of risks, converging with the opinion of other authors [13, 14, 15].

For $76.2 \%$ of the respondents, the Risk Management in Scrum is different from that practiced in traditional methodologies. The respondents mentioned that there is no defined processes for risk management in the Scrum framework, while traditional methodologies have bureaucratic processes to implement this practice.

Regarding the effectiveness of risk management, most respondents $(48.86 \%$ ) believe that it depends on the project team profile. The respondents justified that Scrum can bring better results in teams with great experience in risk management. However, $33.33 \%$ of respondents believe that risk management in Scrum is more effective, independently of team's profile, because the risks are treated more often during the framework ceremonies.

According to $38.10 \%$ of respondents, the integration of traditional practices of risk management to Scrum would be effective because the use of specific practices of Risk Management would improve this process in Scrum projects. On the other hand, $28.57 \%$ of respondents believe that the effectiveness of this integration would be low, because the Scrum approach differs from that presented by traditional 
methods, which would leave the work heavy and slow rather than agile.

For $23.81 \%$ of the respondents believe that the effectiveness of this integration would depend on how it is performed. The adaptation of risk management is necessary to preserve principles presented by the Agile Manifesto [55]. Another justification of the respondents is that traditional risk management methodologies would bring greater efficiency to the Scrum depending on project risk, where higher risk projects would benefit from this integration.

\section{CONCLUSIONS}

This research identified that the two most common Risk Management practices in Scrum projects are related to aspects of communication and individual behavior. On the other hand, the two less common identified practices in Scrum refers to the implementation of formal processes and documentation and to the Scrum Master responsabilities. Futhermore, Scrum projects should not have formal planning and the Scrum Master should not focus on the implementation of formal processes.

The analyzed results indicate that the Risk Management performed in Scrum projects is different of its application proposal on traditional methodologies. The framework possess native resources that contribute to risks identification and follow-up frequently, but the effectiveness of Risk Management in Scrum projects would depend on the team's experience.

The other classic Risk Management processes, such as, planning, qualitative and quantitative analysis and risks response plans, must be incorporated and adapted to Scrum. It is important this adaptation to be performed preserving the benefits from this framework and The Agile Manifesto principles. Since it is an empiric framework, the effective Risk Management application on Scrum relies on the project team's maturity. This scenario is empowered by the absence of some or many Risk Management formal processes.

For the accomplishment of further researches, it is suggested to carry out grouping of the Risk Management practices according to artifacts, ceremonies and roles on Scrum. Can also be carried out the identification of the Scrum items which most contribute to Risk Management, performing the mapping and highlighting point of attention on dealing with project risks.

\section{ACKNOWLEDGMENTS}

The authors need to express their acknowledgments to three Brazilian research agencies: the CAPES Foundation, CNPq and FAPEMIG, and especially all interviewees and reviewers. We also thank the anonymous SEKE reviewers whose comments and suggestions brought us to an improved version of this paper.

\section{REFERENCES}

[1] P.L Bannerman, "Risk and risk management in software projects: A reassessment" in The Journal of Systems and Software, vol. 81, n. 12, 2008, pp. 2118-2133.

[2] R. Kaur and J. Sengupta, "Software Process Models and Analysis on Failure of Software Development Projects" in International Journal of Scientific \& Engineering Research, vol. 2, n. 2, 2011, pp. 1-4.

[3] Forrester Research, "Software and Services in Large Enterprises" in Business Technographics, Forrester Research, 2005.

[4] D. West and T. Grant, "Agile Development: Mainstream Adoption Has Changed Agility" in Forrester Research, 2010.

[5] J. Erickson, K. Lyytinen, and K. Siau, "Agile Modeling, Agile Software Develpment, and Extreme Programming: The State of Research" in Journal of Database Management, vol. 16, n. 4, 2005, pp. 88-100.
[6] E.T. Alharbi and M.R.J. Qureshi, "Implementation of Risk Management with SCRUM to Achieve CMMI Requirements" in I.J. Computer Network and Information Security, vol. 11, 2014, pp. 20-25.

[7] J. Garzás and M.C. Paulk, "A case study of software process improvement with CMMI-DEV and Scrum in Spanish companies" in Journal of Software: Evolution and Process, vol. 25, n. 12, 2013, pp. 1325-1333.

[8] Z. Racheva, M. Daneva, "Reprioritizing the Requirements in Agile Software Development: towards a Conceptual Model from Clients' Perspective" in The 21th International Conference on Software Engineering \& Knowledge Engineering, 2009, pp. 73-80.

[9] R.N. Charette, "Why software fails" in IEEE Spectrum, vol. 42, n. 9, 2005, pp. 42-49.

[10] A.A.M. Chowdhury and S. Arefeen, "Software Risk Management: Importance and Practices" in International Journal of Computer and Information Technology (IJCIT), vol. 02, n. 01, 2011, pp. 49-54.

[11] SEI - Software Engineering Institute. CMMI - Capability Maturity Model Integration. Version 1.3, Pittsburgh, PA, Carnegie Mellon University, USA, 2010.

[12] B. de Wet and J.K. Visser, "An evaluation of software project risk management in South Africa" in South African Journal of Industrial Engineering, vol. 24, n. 1, 2013, pp. 14-28.

[13] S.K. Khatri, K. Bahri, and P. Johri, "Best Practices for Managing Risk in Adaptive Agile Process" in International Conference on Reliability, Infocom Technologies and Optimization (ICRITO), 2014, pp. 1-5.

[14] A. Moran, "Agile Risk Management" in SpringerBriefs in Computer Science, 2014, pp. 33-60.

[15] J. Nyfjord and M. Kajko-Mattsson, "Outlining a model integrating risk management and Agile software development" in Proceedings of the 34th EUROMICRO Conference on Software Engineering and Advance Applications IEEE Computer Society, 2008, pp. 476-483.

[16] E. Odzaly, D. Greer, D. Stewart, Lightweight Risk Management in Agile Projects in: The 26th International Conference on Software Engineering \& Knowledge Engineering, 2014, pp. 576-581

[17] H. Hijazi, T. Khdour, A. Alarabeyyat, "A Review of Risk Management in Different Software Development Methodologies" in International Journal of Computer Applications, vol. 45, n. 7, 2012, pp. 8-12.

[18] B.G. Tavares, "Risk Management Analysis in Software Projects that Use the Scrum Framework", Masters Dissertation - Federal University of Itajubá, Itajubá, 2015.

[19] P.G. Smith and R. Pichler, "Agile Risks, Agile Rewards" in Software Development Magazine, vol. 13, 2005, pp. 50-53.

[20] A.S.C. Marçal, B.C.C Freitas, F.S.F Soares, A.D. Belchior, "Mapping CMMI Project Management Process Areas to SCRUM Practices" in Software Engineering Workshop, 2007 pp. 13-22.

[21] J.R. Menezes, C.M.G Gusmão, and H. Moura, "Defining Indicators for Risk Assessment in Software Development Projects" in CLEI Electronic Journal, vol. 16, n. 1, 2013.

[22] C.R. Jakobsen and K.A. Johnson, Mature Agile with a Twist of CMMI in Agile '08 Conference, 2008.

[23] V. Szalvay, "Glossary of Scrum Terms", Available at: https://www.scrumalliance.org/community/articles/2007/march/glossary -of-scrum-terms\#1126. Accessed on: February 09th 2016.

[24] M. Tomanek and J. Juricek, "Project Risk Management Model Based on PRINCE2 and Scrum Frameworks" in The International Journal of Software Engineering \& Applications (IJSEA), vol. 6, n. 1, 2015, pp. 8188.

[25] K. Schwaber and J. Sutherland Jeff, "The Scrum Guide" in Scrum.org, 2013.

[26] S.P. Ravi, B. Reddaiah, L.S. Movva, and R. Kilaparthi, "A Critical review and empirical study on success of risk management activity with respect to Scrum" in Engineering Science and Technology: An International Journal (ESTIJ), vol. 2, n. 3, 2012, pp. 467-473.

[27] European Comission. User guide to the SME definition. Internal Market, Industry, Entrepreneurship and SMEs, Maio, 2015.

[28] A.J. Shenhar and D. Dvir, "Reinventing Project Management: the diamond approach to successful growth and innovation" in Harvard Business School Press, 2007.

[29] M. Silva and C. Jeronimo. "From Taylor to Tailoring - In Pursuit of the Organizational Fit" in Second International Scientific Conference on Project Management in the Baltic Countries, 2013.

[30] B.J. Sauser, R. Reilly, and A.J. Shenhar, "Why projects fail? How contingency theory can provide new insights - A comparative analysis of 
NASA's Mars Climate Orbiter loss" in International Journal of Project Management, vol. 27, n. 7, 2009, pp. 665-679.

[31] D. Dvir, A. Sadeh, and A. Malach-pines, "The fit between entrepreneurs' personalities and the profile of the ventures they manage and business success: An exploratory study" in The Journal of High Technology Management Research, vol. 21, n. 1, 2010, pp. 43-51.

[32] M. Frank, A. Sadeh, and S. Ashkenasi, "The Relationship Among Systems Engineers' Capacity for Engineering Systems Thinking, Project Types, and Project Success" in Project Management Journal, vol. 42, n. 5, 2011, pp. 31-41.

[33] B. Vanathi, T. Saravanan, and M. Nagarajan, "Growth of Literature in Chemistry Research Output in Tamil Nadu Universities: A Scientometric Study (1989 -2015)" in Journal of Advances in Library and Information Science, vol. 43, n. 3, 2015, pp. 187-190.

[34] S. Mukherjee, B. Uzzi, B. Jones, and M. Stringer, "A New Method for Identifying Recombinations of Existing Knowledge Associated with High-Impact Innovation" in Journal of Product Innovation Management, vol. 33, n. 2, 2016, pp. 224-236.

[35] P. Muñoz, M. Ontiveros, S. De La Barquera, and A. L. Packer, "Action Lines for the Years 2014-2016 with the Objective of Increasing the Visibility of the SciELO Network Journals and Collections" in Reunião sobre linhas de ação para o desenvolvimento dos periódicos indexados no SciELO. Santiago de Chile, 2013, pp. 25-27.

[36] J. M. Swales and C. Leeder, "A reception study of the articles published in English for Specific Purposes from 1990-1999" in English for Specific Purposes, vol. 31, 2012, pp. 137-146.

[37] J. Cusker, "Elsevier Compendex and Google Scholar: A Quantitative Comparison of Two Resources for Engineering Research and an Update to Prior Comparisons" in The Journal of Academic Librarianship, vol. 39, n. 3, 2013, pp. 241-243.

[38] J. F. Hair, B. Babin, A.H. Money, and P. Samouel, "Fundamentos de métodos de pesquisa em administração", Porto Alegre, Bookman, 2005.

[39] Y. Kwak and J. Stoddard, "Project risk management: lessons learned from software development environment" in Technovation, vol. 24, n. 11, 2004, pp. 915-920.

[40] A. Bryman and E. Bell, "Business research methods", $2^{\mathrm{a}}$ ed., New York: Oxford University Press, 2007.

[41] E.G. Carmines and R.A. Zeller, "Reability and Validity Assessment", Londres, Sage, 1979.

[42] D.R. Heise and G.W. Bohrnstedt, "Validity, Invalidity and Reliability", in EF Borgatta, G Bohrnstedt (Eds.). Sociological methodology, 1970, pp. 104-129.

[43] C. Fan, Y. Yu, "BBN-based software project risk management" in The Journal of Systems and Software, n. 73, 2004, pp. 193-203.
[44] M.O. Barros, C.M.L Werner, and G.H. Travassos, "Supporting risks in software project management" in The Journal of Systems and Software, vol. 70, n. 1-2, 2004, pp. 21-35.

[45] H. Barki, S. Rivard, and J. Talbot, "An Integrative Contingency Model of Software Project Risk Management" in Journal of Management Information Systems, vol. 17, n. 4, 2001, pp. 37-69.

[46] T. Dingsøyr, G.K. Hanssen, and T. Dybå, "Developing Software with Scrum in a Small Cross-Organizational Project" in Proceedings of the 13th European conference on Software Process Improvement, Joensuu, Finland, 2006, pp. 11-13.

[47] N.B. Moe, T. Dingsøyr, T. Dybå, "A teamwork model for understanding an agile team: A case study of a Scrum project" in Information and Software Technology, n. 52, 2010, pp. 480-491.

[48] T. Dyba and T. Dingsøyr, "Empirical studies of agile software development: A systematic review" in Information and Software Technology, vol. 50, n. 9-10, 2008, pp. 833-859.

[49] C. Felker, R. Slamova, J. Davis, "Integrating UX with Scrum in an Undergraduate Software Development Project" in SIGCSE '12 Proceedings of the 43rd ACM technical symposium on Computer Science Education, 2012, pp. 301-306.

[50] J. Ahola, C. Frühwirth, M. Helenius, L. Kutvonen, J. Myllylahti, T. Nyberg, A. Pietikäinen, P. Pietikäinen, J. Röning, S. Ruohomaa, C. Särs, T. Siiskonen, A. Vähä-Sipilä and V. Ylimannela, "Handbook of The Secure Agile Software Development Life Cycle", University of Oulu, 2014.

[51] R. Hoda, P. Kruchten, J. Noble, and S. Marshall. "Agility in Context" in Proceedings of the ACM International Conference on Object Oriented Programming Systems, Languages, and Applications (OOPSLA), 2010, pp. 74-88.

[52] O. Ktata and G. Lévesque, "Designing and Implementing a Measurement Program for Scrum Teams: What do agile developers really need and want?" in 3rd Conference on Computer Science and Software Engineering (C3S2E), Montreal, QC, Canada. Association for Computing Machinery, 2010, pp. 101-107.

[53] M. Lárusdóttira, Å. Cajanderb, and J. Gulliksenc, "Informal feedback rather than performance measurements - user-centred evaluation in Scrum projects" in Behaviour \& Information Technology, vol. 33, n. 11, 2014, pp. 1118-1135.

[54] M.R.J Qureshi, and A. Albarqi, "Proposal of New PRORISK Model for GSD Projects" in International Journal of Information Technology and Computer Science, vol. 6, 2015, pp. 38-44.

[55] The Agile Manifesto. Principles behind the Agile Manifesto. Available at: http://www.agilemanifesto.org/principles.html. Accessed on: February 20th 2016. 